\title{
Fulminant reversible cerebral vasoconstriction syndrome in post-partum female
}

\author{
Rambir Singh, Shilpi Mittal*, Alsaba Khan, Bharat Gupta, \\ Narendra Kardam, Kushal Gehlot
}

Department of Radiodiagnosis, R.N.T. Medical College, Udaipur, Rajasthan, India

Received: 25 May 2016

Accepted: 13 June 2016

\section{*Correspondence:}

Dr. Shilpi Mittal,

E-mail: doc.shilpimittal@gmail.com

Copyright: (C) the author(s), publisher and licensee Medip Academy. This is an open-access article distributed under the terms of the Creative Commons Attribution Non-Commercial License, which permits unrestricted non-commercial use, distribution, and reproduction in any medium, provided the original work is properly cited.

\begin{abstract}
Reversible cerebral vasoconstriction syndrome (RCVS) is a clinical and radiologic syndrome that represents a common presentation of a diverse group of disorders. Call-Fleming syndrome which is a part of RCVS group. We present a case of 30 year old primigravida who developed thunderclap headache followed by seizures on her day 1 of postpartum period. MRI revealed left anterior cerebral artery infarct with vasoconstriction of bilateral internal carotid arteries and its branches. She was managed conservatively. Follow up on $25^{\text {th }}$ day revealed complete reversal of vasoconstriction in above mentioned arteries which confirmed the diagnosis of Call-Fleming syndrome. Patient had residual aphasia and right lower limb paresis on 2 months follow up.
\end{abstract}

Keywords: RCVS, Call-Fleming syndrome, Pregnancy

\section{INTRODUCTION}

Hepatitis E infection is endemic in developing regions of Reversible cerebral vasoconstriction syndrome (RCVS) is a recently described term. It is a large group of various clinical entities that includes multiple different entities with a common clinical presentation and radiological appearance. Clinically these patients present with thunderclap headache and may not have neurological deficits. We present a case of Call-Fleming syndrome which is a part of reversible cerebral vasoconstriction syndrome (RCVS) group and is thought to be of idiopathic origin. It is considered a rare phenomenon that was first reported by call and Fleming in 1980's. Reversible cerebral vasoconstriction syndrome (RCVS) is a clinical and radiologic syndrome whose primary features include the hyper-acute onset of severe headache and segmental vasoconstriction of cerebral arteries that resolves by 3 months. ${ }^{1-5}$ Common imaging findings are diffuse segmental cerebral vasoconstriction of the intracranial internal carotid arteries, basilar artery and arteries of the circle of Willis that spontaneously resolves in weeks to months. Although the patho-physiology of RCVS remains unknown, the prevailing hypothesis involves a transient disturbance in vascular tone. ${ }^{6,7}$ This alteration in vascular tone may be spontaneous or evoked by various exogenous or endogenous factors. Pregnancyrelated hormonal effects are known to alter vascular tone. $^{8}$ We report a case of RCVS in which the patient presented in immediate post-partum period.

\section{CASE REPORT}

We present a case of a 30 years old primigravida after normal vaginal delivery of a healthy male child on day 1 postpartum developed acute onset severe headache followed by seizures. On physical examination, her blood pressure was elevated at 200/98 $\mathrm{mm}$ of $\mathrm{Hg}$. 
Her baseline hematological work-up and vitals including blood pressure were within the normal limits during the antenatal and natal periods. There was no past as well as antenatal history of trauma, fever, fits, or blurring of vision. Her past medical history did not reveal any comorbid medical conditions and she had not had any similar episodes in the past. A further detailed personal history revealed that there was no evidence of substance abuse or any sort of addictions. A fundoscopy examination was within normal limits. Neurological examinations revealed that the patient had developed right lower limb paresis and aphasia and was managed with conservative medical therapy.

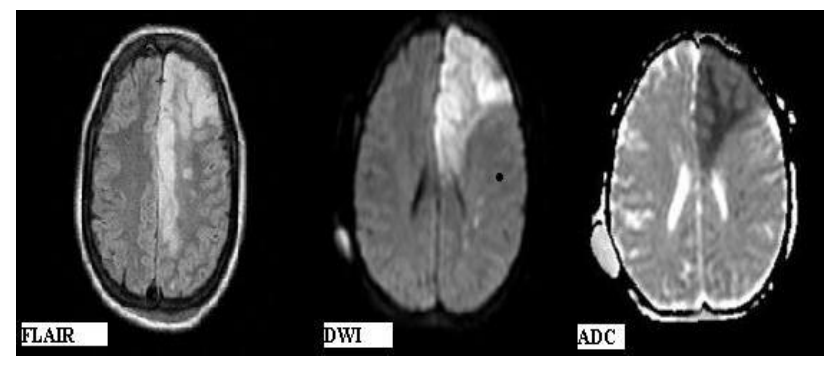

Figure 1: MRI of acute infarct in left frontal lobe appearing hyper intense on FLAIR and area of restriction on diffusion and $\mathrm{ADC}$ sequences.

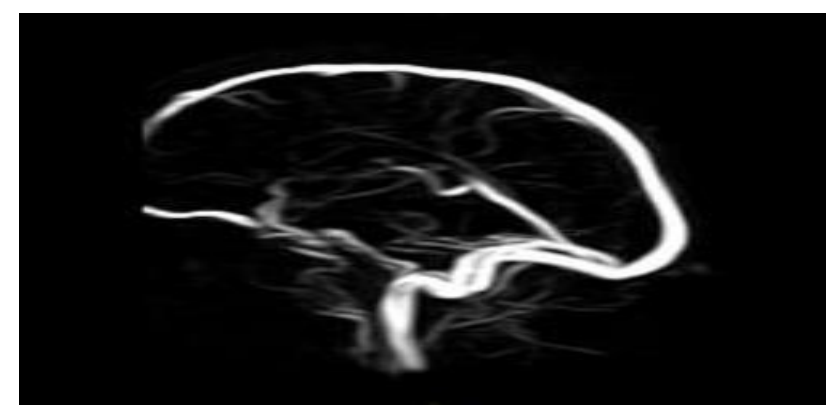

Figure 2: MR venogram of the patient which was normal.

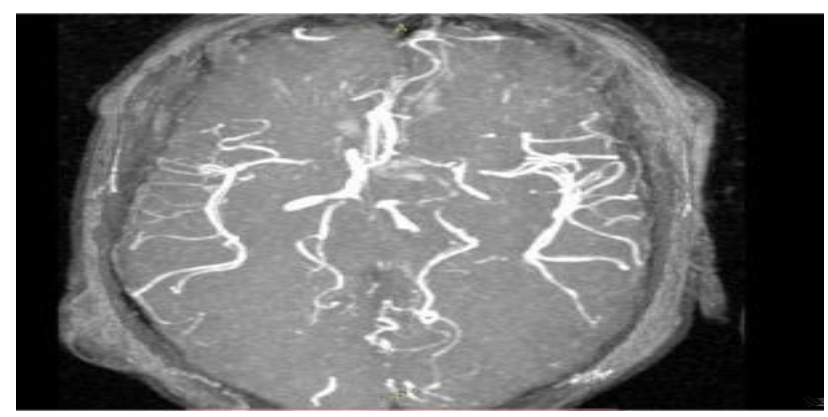

Figure 3: MR angiogram vasoconstriction of left internal carotid artery, M1 segment of bilateral middle cerebral arteries, left anterior cerebral artery and P1 segment of bilateral posterior cerebral arteries.

CSF examination and NCCT of the brain was unremarkable at the time. MRI was planned and revealed acute ischemic infarction in left frontal lobe (Figure 1), MRV of the patient was normal (Figure 2) and MRA showed vasospasm of bilateral internal carotid arteries, anterior and middle cerebral arteries, basilar artery and arteries of the circle of Willis (Figure 3). A probable diagnosis of RCVS was made and the patient was intensively monitored and managed conservatively. She was treated with nimodipine, a calcium channel blocker, and gradually her headache resolved and there was partial improvement in her neurologic functions.

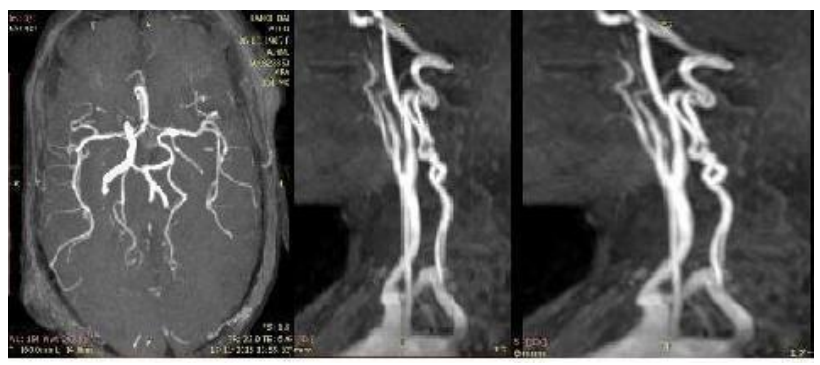

Figure 4: Follow up MRA on $25^{\text {th }}$ day, reversal of vasospasm in above mentioned arteries.

Follow-up MRA on $25^{\text {th }}$ day (Figure 4) showed almost complete reversal of vasospasm in above mentioned arteries. There was sub-acute infarct in above mentioned territory of brain. Patient had slight improvement in aphasia and there was persistent right lower limb paresis which showed minimal improvement on 2 months follow up.

\section{DISCUSSION}

RCVS is a cerebro-vascular disorder and it encompasses a large group of conditions which are characterized by, as the name suggests, intra-cerebral vascular spasms that are reversible. It encompasses the various syndromes like Call-Fleming syndrome, migrainous vasospasm, benign angiopathy of the central nervous system (CNS) and drug-induced arteritis. ${ }^{9}$ It can also be seen in association with postpartum status, exposure to vasoactive substances, catecholamine secreting tumors, exposure to immunosuppressant's, blood products or blood transfusion, extra- or intracranial large artery disorders, head trauma, neurosurgical procedures, strenuous physical activities, and deep diving in a swimming pool. ${ }^{10}$

In 1988, Gregory Call and Marie Fleming described a unique clinical and radiographic syndrome in a small case series of 4 patients presenting with acute headache and reversible cerebral artery vasoconstriction. ${ }^{11}$ In this small series, the authors demonstrated a wide range of possible clinical outcomes, from complete resolution of symptoms to permanent disability with hemi paresis and/or cortical blindness. The eponym "Call-Fleming syndrome" was subsequently used to describe the entity.

The radiographic appearance is of constriction of the arteries arising or forming the circle of Willis and their 
branches. The post-stenotic segments show dilatation. This may give an appearance of beaded or sausageshaped arteries. This appearance with the resolution on the follow-up imaging is classical for this condition. ${ }^{12}$

Thunderclap headache, seizures, and occasionally visual or sensorimotor 6 deficits in combination with normal cerebrospinal fluid (CSF) and segmental arterial vasoconstriction are typical for RCVS. ${ }^{11}$ Reversibility of vasoconstriction within two months and absence of vacuities further support this diagnosis. ${ }^{9,13}$ Although the patho-physiology of RCVS remains unknown, the prevailing hypothesis involves a transient disturbance in vascular tone. ${ }^{6,7}$ This alteration in vascular tone may be spontaneous (primary RCVS) or evoked by various exogenous or endogenous factors (secondary RCVS). There appears to be interaction between sympathetic over-activity and endothelial dysfunction, resulting in dysautoregulation. ${ }^{6}$ Pregnancy-related hormonal effects are known to alter vascular tone.

Timely and accurate diagnosis of RCVS is essential to ensuring appropriate patient care and avoiding unnecessary diagnostic tests. However, the diagnosis can be challenging because its signs and symptoms can overlap those of better known disorders of the central nervous system, including aneurysmal subarachnoid hemorrhage and primary angiitis of the CNS. ${ }^{1,2,9,14,15}$ An approach to investigation of acute severe headache in postpartum female includes, a non-contrast CT brain to exclude subarachnoid and intra-cerebral hemorrhage. Further, the LP was performed looking for evidence of CNS infection, subarachnoid hemorrhage, or primary angiitis of central nervous system (PACNS). A distinguishing feature of RCVS is an initially normal CSF result. Depending on the history, CT angiography at the time of a non-contrast CT may be warranted, looking for evidence of RCVS, cervical artery dissection, or cerebral venous thrombosis. Angiographic changes in cerebral arteries, described as a "string of beads," are highly characteristic of RCVS. CT angiography (CTA) is readily available, fast, and can be performed immediately after an initial non-contrast CT, however MRI with angiography and venography has advantages over CTA as the next radiological investigation following a normal CT. ${ }^{16}$ A CTA or MRA may follow a non-contrast CT however, if both of these are non-diagnostic and clinical suspicion of RCVS exists, a DSA should follow.

Follow-up imaging may be with MRA or DSA should be done to demonstrate reversal of vasoconstriction. Therefore, a diagnosis of RCVS can be made. Common imaging findings are diffuse segmental cerebral vasoconstriction of the intracranial internal carotid arteries, basilar artery and arteries of the circle of Willis that spontaneously resolves in weeks to months.

In our case, a healthy 40 years old primigravida, after an uncomplicated pregnancy and childbirth, on day 1 postpartum developed sudden, severe, and persistent headache associated with generalized seizure and elevated blood pressure. Initial NCCT of the brain and CSF examination was unremarkable. MR angiography revealed intra-medullary infarctions with vasoconstriction of bilateral internal carotid arteries and its branches, which showed reversal of vasospasm on subsequent MRA. Therefore, probable diagnosis of Call-Fleming syndrome was made.

The most important differential diagnosis to RCVS is primary angiitis of the CNS (PACNS). However, PACNS is more prevalent in men than in women and has a median age range of 40 to 60 years. Moreover, the onset of symptoms is often insidious and CSF examination may demonstrate leukocytosis and elevated protein levels. ${ }^{17}$ As all this was absent in our patient, the diagnosis of PACNS was discarded. In addition, CNS imaging did not support a diagnosis of angiitis.

The outcome of our patient was good with some residual deficits. However, severe disabling strokes, SAH, and even death have been reported. $6,9,18-20$

\section{Treatment}

Therapeutic management is by calcium channel blockers; however, they should be used with caution as there is a risk of infarction in the watershed regions. ${ }^{9,21}$ Short course of high-dose gluco-corticoid and magnesium sulfate as treatment are also advocated. Due to spontaneous resolution, the prognosis is good. ${ }^{9}$ Identification and discontinuation of the trigger agents is advocated. $^{22}$

\section{Funding: No funding sources \\ Conflict of interest: None declared \\ Ethical approval: Not required}

\section{REFERENCES}

1. Ducros A. L37: reversible cerebral vasoconstriction syndrome distinction from CNS vasculitis. Presse Med. 2013;42(4 pt 2):602-04.

2. Ducros A, Bousser MG. Reversible cerebral vasoconstriction syndrome. Pract Neurol. 2009;9:256-67.

3. Gupta S, Zivadinov R, Ramasamy D, Ambrus JL. Reversible cerebral vasoconstriction syndrome (RCVS) in antiphospholipid antibody syndrome (APLA): the role of centrally acting vasodilators case series and review of literature. Clin Rheumatol. 2014;33:1829-33.

4. Marder CP, Donohue MM, Weinstein JR, Fink KR. Multimodal imaging of reversible cerebral vasoconstriction syndrome: a series of 6 cases. AJNR Am J Neuroradiol. 2012;33:1403-10.

5. Sheikh HU, Mathew PG. Reversible cerebral vasoconstriction syndrome: updates and new perspectives. Curr Pain Headache Rep. 2014;18:414. 
6. Ducros A, Boukobza M, Porcher R, Sarov M, Valade $\mathrm{D}$, Bousser MG. The clinical and radiological spectrum of reversible cerebral vasoconstriction syndrome: a prospective series of 67 patients. Brain. 2007;130(Pt-12):3091-101.

7. Schwedt TJ, Matharu MS, Dodick DW. Thunderclap headache. Lancet Neurol. 2006;5:621-31.

8. Newell CP, Seller C, Vizhi M, Turner N. Case report: spontaneous coronary artery dissection during elective caesarean section under spinal anaesthesia. Anaesthesia. 2011;66:615-9.

9. Calabrese LH, Dodick DW, Schwedt TJ, Singhal AB. Narrative review: reversible cerebral vasoconstriction syndromes. Ann Intern Med. 2007; 146:34-44.

10. Tienviboon C, Punyagupta S, Pongtarakulpanit A, Prichanond S. Reversible cerebral vasoconstriction syndrome with increased intracranial pressure, probably related to altitude changes and windy winter travelling. J Med Assoc Thai. 2011;94:622-8.

11. Call GK, Fleming MC, Sealfon S, Levine H, Kistler JP, Fisher CM. Reversible cerebral segmental vasoconstriction. Stroke. 1988;19:1159-70.

12. Moustafa RR, Allen CM, Baron JC. Call-Fleming syndrome associated with subarachnoid haemorrhage: Three new cases. J Neurol Neurosurg Psychiatry. 2008;79:602-5.

13. The International Classification of Headache Disorders: $2^{\text {nd }}$ edn. Cephalalgia. 2004;24(Suppl 1):9160.

14. Calic Z, Choong H, Schlaphoff G, Cappelen-Smith C. Reversible cerebral vasoconstriction syndrome following indomethacin. Cephalalgia. 2014;34:11816.

15. Grooters GS, Sluzewski M, Tijssen CC. How often is thunderclap headache caused by the reversible cerebral vasoconstriction syndrome? Headache. 2014;54:732-5.

16. Chen SP, Fuh JL, Wang SJ. Reversible cerebral vasoconstriction syndrome: an under-recognized clinical emergency. Therapeutic Advances in Neurological Disorders. 2010;3(3):161-71.

17. Birnbaum J, Hellmann DB. Primary angiitis of the central nervous system. Arch Neurol. 2009;66:704-9.

18. Fletcher JJ, Kramer AH, Bleck TP, Solenski NJ. Overlapping features of eclampsia and postpartum angiopathy. Neurocrit Care. 2009;11:199-209.

19. Geraghty JJ, Hoch DB, Robert ME, Vinters HV. Fatal puerperal cerebral vasospasm and stroke in a young woman. Neurology. 1991;41:1145-7.

20. Singhal AB, Kimberly WT, Schaefer PW, HedleyWhyte ET. Case records of the massachusetts general hospital. Case 8-2009. A 36-yearold woman with headache, hypertension, and seizure 2 weeks postpartum. N Engl J Med. 2009;360:1126-37.

21. Karmacharya R, Singh M, Rawal S. Call Fleming syndrome: case report. Nepal J Neurosci. 2008;5:601 .

22. Cvetanovich GL, Ramakrishnan P, Klein JP, Rao VR, Ropper AH. Reversible cerebral vasoconstriction syndrome in a patient taking citalopram and hydroxycut: a case report. J Med Case Rep. 2011;5:548.

Cite this article as: Singh $\mathrm{R}$, Mittal $\mathrm{S}$, Khan A, Gupta B, Kardam N, Gehlot K. Fulminant reversible cerebral vasoconstriction syndrome in post-partum female. Int J Reprod Contracept Obstet Gynecol 2016;5:2481-4. 